\title{
Influência das doenças periodontais sobre as cardiopatias coronarianas
}

\author{
Tatiana Dalla Costa ${ }^{1}$ \\ Gilberto Ferreira da Silva Júnior² \\ Marilisa Lugon Ferreira Terezan ${ }^{3}$
}

\begin{abstract}
Resumo
Opresente estudo teve por objetivo realizar uma revisão da literatura referente à associação entre infecçôes dentárias, mais especificamente a doença periodontal, e as cardiopatias coronarianas, apresentando dados epidemiológicos que sugerem essa associação, além dos potenciais mecanismos biológicos responsáveis por sua possivel atuação como fator de risco. A análise dos trabalhos pesquisados nos permite concluir que, apesar de estar sugerida epidemiologicamente essa associação às condiçōes cardiovasculares, a doença periodontal ainda não pode ser considerada como um fator de risco real para aquela. Foi concluído também que as possivveis explicações biológicas para tal associação podem estar relacionadas a um aumento da atividade trombogênica, dado pelo aumento da viscosidade sangüinea e maior agregação plaquetária frente a alguns patógenos periodontais presentes nas bacteremias, bem como da ação direta de algumas bactérias periodontopatogênicas na formação da placa aterosclerótica e de alguns mediadores inflamatórios aumentados na doença periodontal, os quais seriam também considerados como marcadores do risco periodontal.
\end{abstract}

Palavras-chave: doenças periodontais; cardiopatias coronarianas.

\section{INTRODUÇÃO}

As doenças cardiovasculares, especialmente as cardiopatias coronarianas, figuram entre as principais causas de óbito na sociedade contemporânea. ${ }^{1}$ As manifestações clínicas das cardiopatias coronarianas (CC) incluem: morte cardíaca súbita, anginas de peito estável e instável, infarto agudo do miocárdio e insuficiência cardíaca congestiva. Essas manifestações resultam, mais freqüentemente, de aterosclerose nos vasos coronários epicárdicos. A aterosclerose humana é um processo crônico, progressivo e sistêmico, caracterizado por uma resposta inflamatória e fibroproliferativa da parede arterial. (2)

A causa da aterosclerose coronária não é conhecida até o momento, mas parece estar ligada a vários fatores de risco. Entre esses, os mais freqüentemente mencionados são idade, sexo, história familiar, nível lipídico no soro, dieta, hipertensão, hábito de fumar e diabetes. Foi relatado que um único fator de risco não poderia ser responsável pelo desenvolvimento da aterosclerose,

\footnotetext{
${ }^{1}$ Acadêmica do Curso de Especialização em Periodontia da Faculdade de Odontologia da UERJ. Rio de Janeiro - RJ

2 Professor de Periodontia da FESO. Rio de Janeiro - RJ

${ }^{3}$ Coordenadora do Curso de Especialização em Periodontia da Faculdade de Odontologia da UERJ. Rio de Janeiro - RJ

Correspondência para / Correspondence to:

Gilberto Ferreira da Silva Júnior

Rua Engenheiro Ernani Cotem, 55/apto 203 -Tijuca.

20510-260. Rio de Janeiro - RJ - Brasil.

Tel.: (21) 22082125 / 99457136.

E-mail: gilbertjunior@yahoo.com.br.
} 
sendo necessário uma associação de vários fatores para o seu desenvolvimento. (2)

Entretanto tais fatores de risco não explicam a presença da aterosclerose coronária em um grande número de pacientes - cerca de $1 / 3$ - e as infecçôes localizadas que resultam em reaçôes inflamatórias crônicas foram sugeridas como um dos mecanismos que fundamentam a doença nesses indivíduos. (3)

Existe hoje, na literatura, uma série de fatores sistêmicos inflamatórios e hemostáticos associados à doença cardiovascular. Níveis sangüíneos elevados para proteína c-reativa (PCR), leucócitos, fibrinogênio, fator de von Willebrand e outros fatores inflamatórios têm sido freqüientemente relacionados com alto risco para doença cardiovascular, sendo considerados contribuintes para a formação do ateroma. $(4,5)$

A periodontite é uma infecção multifatorial, causada por um grupo de bactérias gram-negativas presentes na superfície dos dentes e no biofilme da placa bacteriana. A resposta do hospedeiro às infecções periodontais resulta em uma produção local de citocinas e mediadores biológicos, inclusive interleucinas e prostaglandinas, bem como na indução da produção de anticorpos séricos, numa resposta sistêmica. (6)

Em vista da forte associação da placa bacteriana com as infecções periodontais, da natureza crônica dessas doenças e da resposta local e sistêmica do hospedeiro ao ataque microbiano, é razoável a hipótese de que essas infecções possam influenciar a saúde geral e o curso de algumas doenças sistêmicas. Assim sendo, diversos estudos têm buscado estabelecer a prevalência e os mecanismos de associação entre as doenças cardiovasculares e as doenças periodontais.

\section{REVISÃO DE LITERATURA}

A associação entre a periodontite e a aterosclerose começou a ser relatada ainda na década de 60. Embora sem grande valor estatístico em função do tamanho da amostra, o trabalho de Mackenzie e Millard (7) reportou a primeira indicação de uma possível associação entre aterosclerose e doença periodontal.
Estudos recentes consideram que a natureza infecciosa das doenças periodontais poderia produzir a injúria inicial desencadeadora da aterosclerose, ou mesmo provocar o agravamento do processo aterosclerótico pré-existente. Essas evidências foram sugeridas em estudos de coorte retrospectivo, transversais e caso-controle, realizados por Mattila e colaboradores $(8,9)$, De Stefano e colaboradores (10), e Beck e colaboradores. (3) Esses estudos verificaram que a associação entre as condiçōes bucais e aterosclerose é consistente em diferentes amostras de populações, e também demonstraram que as condiçōes bucais precedem os eventos coronários.

Beck e colaboradores (3) observaram, durante um período de 18 anos, que os níveis de perda óssea alveolar estão associados à alta incidência de doenças cardiovasculares fatais ou não, assim como a história de derrame.

Segundo Joshipura (11), a saúde dental é um importante fator ou indicador de risco para doenças cardiovasculares, quando associado com diabetes, fumo, nível de colesterol elevado e vida sedentária.

Paunio e colaboradores (12) investigaram a associação entre o número de dentes perdidos e doenças isquêmicas diagnosticadas, observando que a perda dentária tem associação significativa com angina péctoris ou infarto do miocárdio, após o controle para os fatores de confusão.

Hujoel e colaboradores (5) avaliaram o risco para doenças ateroscleróticas coronarianas em pessoas com periodontite, com gengivite e sem doença periodontal. Após ajustes para os fatores de risco conhecidos, os resultados desse estudo não mostraram evidências de que a gengivite e a periodontite estão associadas à doença cardiovascular.

Os mesmos autores do trabalho anterior elaboraram outro estudo (13), com a finalidade de determinar se indivíduos nos quais foi eliminada toda infecção dentária em potencial, ou seja, edentados, teriam o risco para doença cardíaca coronariana reduzido ao longo do tempo, em comparação com portadores de periodontite. Os resultados indicaram que a eliminação das infecções dentárias crônicas não levou a um decréscimo do risco para eventos de doença cardíaca coronariana. 
Juntamente com as avaliações epidemiológicas que relacionam doença periodontal com doenças cardiovasculares, alguns estudos experimentais começaram a ser realizados com o intuito de esclarecer os possíveis mecanismos biológicos responsáveis por essa associação.

Um desses mecanismos considera a possibilidade de que microrganismos da placa bacteriana participem na patogênese da aterosclerose. Dessa forma, alguns estudos têm identificado microrganismos como Actinobacillus actinomycetemcomitans, Bacteróides forsytus, Porphyromonas gingivalis, Streptococus sanguis e Prevotella intermedia nas placas ateromatosas. $(14,15,16)$

Chiu e colaboradores (15) investigaram a presença de vários agentes infecciosos em amostras de placas ateroscleróticas de 33 espécimes da carótida humana. O autor detectou a presença de Porphyromonas gingivalis (42\%) e Streptococus sanguis (12\%), entre outros microrganismos, concluindo que os agentes infecciosos podem alterar a função celular vascular, podendo influenciar na morfologia da placa aterosclerótica, predispondo à ruptura da placa e, dessa forma, desencadeando uma síndrome coronária aguda ou infarto isquêmico agudo.

Haraszthy e colaboradores (16) hipotetizaram que os patógenos periodontais entram na corrente sangüínea durante bacteriemias transitórias, onde podem ter papel no desenvolvimento e na progressão da doença aterosclerótica coronariana.

Brodala (14) avaliou se bacteriemia por Porphyromonas gingivalis induziria inflamação sistêmica e aterosclerose em porcos. Os dados desse estudo mostraram evidências de que bacteriemias recorrentes com Porphyromonas gingivalis induziriam a inflamação sistêmica e a formação do ateroma, num modelo que imita a patologia em humanos.

Outra linha de evidência que compõe o limite entre a relação direta e indireta do risco que a doença periodontal representaria para a aterogênese diz respeito à agregação plaquetária. A agregação das plaquetas é induzida pela proteína de agregação-associação de plaquetas (PAAP), a qual se expressa em algumas cepas de Streptococus sanguis e Porphyromonas gingivalis.
(15) Herzberg (17) relatou que a PAAP poderia interagir com as plaquetas circulantes, provocando tromboembolismo e causando anormalidades pulmonares e cardíacas.

Segundo Fong (4), os marcadores inflamatórios no sangue têm sido relacionados com o risco para a doença cardiovascular, incluindo a PCR , o fibrinogênio, o TNF a e a IL-6. Esses marcadores podem ter seus níveis de concentração sorológica influenciados pela doença periodontal.

Wu e colaboradores (18) examinaram a associação entre a doença periodontal e alguns fatores de risco para a doença cardiovascular: colesterol total, lipoproteína de alta densidadecolesterol, PCR e fibrinogênio. O estudo concluiu que a saúde periodontal precária estaria associada com níveis aumentados de colesterol total, PCR e fibrinogênio, o que poderia explicar, em parte, a ligação entre a doença periodontal e o aumento do risco para a doença cardiovascular.

Loos e colaboradores (19) constataram que a periodontite resulta num aumento do nível sistêmico de PCR, de IL-6 e de leucócitos. Essa elevação dos fatores inflamatórios pode intensificar a atividade inflamatória nas lesôes ateroscleróticas, aumentando potencialmente o risco para eventos cardíacos e cerebrovasculares.

Mc Carthy (20) argumentou que as inflamações e as infecções poderiam induzir a produção de PCR, levando a um significante impacto no risco cardiovascular. Por ser a doença periodontal um dos tipos mais comuns de inflamação ou infecção crônica, é notável que várias análises epidemiológicas tenham concluído que existe correlação entre as doenças periodontais e cardivasculares.

Um outro efeito indireto da infecção periodontal que poderia explicar a associação entre as doenças periodontal e cardíaca diz respeito à hipercoagulabilidade sangüínea. Sabese que a viscosidade sangüínea aumentada pode promover doença cardíaca isquêmica importante e derrames, por aumentar o risco de formação de trombos. O aumento nos níveis de fibrinogênio e da contagem de células brancas, bem como elevações significativas no fator VIII de coagulação - fator de von Willebrand - es- 
tão relacionados à hipercoagulabilidade sangüínea.

Kweider (21) comparou os níveis de fibrinogênio e leucócitos em pacientes com gengivite e periodontite e, no grupo-controle, com saúde bucal. Esse estudo indicou que indivíduos com infecção gengival ou periodontal têm significativa elevação nos níveis de fibrinogênio e leucócitos, comuns às doenças de natureza inflamatória crônica. Já é conhecido que esse processo leva ao aumento relativo do risco de doenças coronarianas.

\section{DISCUSSÃO}

Achados recentes têm recolocado em voga conceitos centenários, segundo os quais as doenças bucais poderiam influenciar o curso de algumas condiçôes patológicas sistêmicas. Um grande número de estudos científicos tem buscado esclarecer a possível relação entre as doenças periodontais e as doenças cardiovasculares. Entretanto, ainda há necessidade de se comprovar se a associação entre o quadro bucal e a condição sistêmica se expressaria realmente em um nível de relação causal, se ocorreria apenas por simultaneidade, ou se refletiria apenas certa suscetibilidade comum, que colocaria o paciente também em risco para tais condições sistêmicas, e, entre elas, mais especificadamente, as alteraçôes cardiovasculares.

A associação entre a periodontite e a aterosclerose começou a ser relatada ainda na década de 60. Embora sem grande valor estatístico em função do tamanho da amostra, o trabalho de Mackenzie e Millard (7), de 1963, reportou a primeira indicação de uma possível associação entre aterosclerose e doença periodontal.

A partir de fins da década de 80 , diversos estudos confirmaram a hipótese da associação entre doença periodontal e doença cardiovascular. Essas evidências foram sugeridas em estudos com os seguintes desenhos: coorte retrospectivo, transversal e caso-controle. (3, 7 , $8,9,10,12)$ Nesses estudos, foi verificado que a associação entre as condiçôes bucais e aterosclerose seria consistente em diferentes amostras de populações, e que as condições bucais precederiam os eventos coronarianos.

No entanto, seria necessário considerar tais conclusões sem perder de vista as limitações metodológicas referentes a esses trabalhos. Um exemplo disso é a falta de padronização entre os critérios adotados para determinação e avaliação de doença periodontal.

Frente aos achados de estudos que têm encontrado relação entre doença periodontal e doença cardiovascular, alguns trabalhos não observaram associações significativas entre as doenças em questão. $(5,11,13)$

Além da preocupação por parte dos pesquisadores em esclarecer a possível relação entre a doença periodontal e a doença cardiovascular, alguns estudos experimentais começaram a ser desenvolvidos para buscar esclarecer os possíveis mecanismos biológicos responsáveis por essa associação.

Dessa forma, tem sido avaliada a possível participação de patógenos periodontais específicos em alterações circulatórias, e a hipótese aceita de que tais patógenos entram na corrente sangüínea refere-se às bacteriemias transitórias. (16) Assim, na presença de infecções mais severas do periodonto, um número muito maior de microrganismos ganharia acesso à circulação.

Quanto aos patógenos periodontais mais freqüentemente encontrados nas lesões ateromatosas, diversos trabalhos têm relatado a presença de Porphyromonas gingivalis, Bacteróides forsytus, Actinobacillus actinomycetemcomitans, Prevotella intermedia e Streptococus sanguis. (14, 15, 16)

Para Chiu e colaboradores (15), os agentes infecciosos poderiam influenciar a morfologia da placa aterosclerótica, por alterar a função celular vascular e desencadear, dessa maneira, uma síndrome coronária aguda ou infarto isquêmico agudo. Outra possibilidade estudada referente à atuação direta dos microrganismos sobre $o$ processo aterosclerótico mostrou que bacteriemias recorrentes por Porphyromonas gingivalis poderiam induzir a inflamação sistêmica e formação do ateroma em porcos. (14)

A agregação plaquetária possui um papel fundamental na trombogênese, e a maioria dos casos de infarto agudo do miocárdio parece ser 
precipitada por tromboembolismo. Tem sido sugerido que bacteriemias transitórias, originadas por infecçôes orais ou periodontais, poderiam induzir à agregação plaquetária. Algumas cepas de Streptococus sanguis e Porphyromonas gingivalis expressam uma proteína designada PAAP, capaz de causar agregação de plaquetas. (17)

Outro mecanismo estudado que objetiva elucidar a associação entre as doenças periodontais e a aterosclerose refere-se aos efeitos indiretos ou mediados pela resposta do hospedeiro no estabelecimento das doenças cardiovasculares. De acordo com Fong (4), alguns marcadores inflamatórios no sangue têm sido relacionados com o aumento para doença cardiovascular, como a PCR, TNF-a e a IL-6. Segundo o mesmo autor, esses marcadores sistêmicos também podem ter seus níveis sorológicos influenciados pela doença periodontal. Estudos recentes têm mostrado aumento no nível da PCR em pacientes com doença periodontal $(18,19,20)$ e que níveis elevados da mesma proteína estão associados com o aumento do risco de isquemia recorrente, podendo ser utilizada como um marcador determinante do prognóstico da doença aterosclerótica coronariana isquêmica.

Finalmente, um outro efeito indireto da infecção periodontal que poderia explicar a associação entre as doenças periodontal e cardíaca diz respeito à hipercoagulabilidade sangüínea. Níveis elevados de fibrinogênio plasmático, células brancas e do fator de von Willebrand resultam no aumento da viscosidade sangüínea. (21) Estudos indicam que indivíduos com doença periodontal apresentam fibrinogênio e, de um modo geral, a contagem de células brancas aumentada, bem como elevações significativas do fator de von Willebrand em indivíduos com higiene oral precária. $(19,21)$ Desse modo, a infecção periodontal promoveria aumento na viscosidade sangüínea e trombogênese e, por conseguinte, um aumento no risco da doença cardíaca isquêmica.

\section{CONCLUSÕES}

Através da análise da literatura estudada, parece-nos válido afirmar que:

1. A saúde oral, mais especificamente a condição periodontal, parece estar fortemente associada com as cardiopatias coronarianas decorrentes de aterosclerose.

2. Apesar da comprovação da associação, os estudos disponíveis não fornecem evidência epidemiológica convincente para uma relação causal entre as doenças periodontais e as cardiopatias coronarianas.

3. As bases biológicas capazes de explicar tal associação ainda não estão elucidadas por completo, embora existam evidências de que patógenos periodontais poderiam atuar sobre a placa ateromatosa, evocando alterações celulares e moleculares, e facilitando o seu desenvolvimento.

4. A bacteriemia determinada pelo acúmulo excessivo de placa bacteriana poderia também provocar um aumento na viscosidade sangüínea e na agregação plaquetária, com conseqüente efeito trombogênico.

5. Mediadores inflamatórios e imunológicos, em especial IL-6 e PCR, parecem ter seus níveis sorológicos aumentados na presença de doença periodontal. Esses têm sido considerados como marcadores para o risco cardiovascular e poderiam, portanto, explicar a possível relação entre as duas doenças.

\title{
Influence of periodontal diseases on coronary heart disease
}

\begin{abstract}
The aim of this paper was to accomplish a review of the literature concerning the association between dental infections, specifically periodontal disease and coronary heart disease, presenting epidemiological data that suggest this association, as well as the potential biological mechanisms responsible for its possible action as
\end{abstract}


a risk factor. The analysis of researched data allows us to conclude that, despite its association to cardiovascular conditions being epidemiologically proved, periodontal disease may not be considered as a real risk factor to that one. It was also concluded that the possible biological explanation to such association should be related to an increased thrombogenic activity, provided by an enhanced blood viscosity and platelet aggregation, related to some periodontal pathogens present in bacteremia, as well as to the direct action of periodontal pathogens in the formation of atherosclerotic plaque and some inflammatory mediators increased in periodontal disease, which would also be considered as periodontal risk markers.

Keywords: periodontal diseases; cardiovascular conditions.

\section{REFERÊNCIAS}

1 FERREIRA, C. Doenças cardiovasculares aterosclerose e fatores de riscos. Disponível em: <http://unifesp.br/dmed/cardio/ch/ cardio.htm>. Acesso: em 6 out. 2004.

2 ANDREOLI, T.E. Doenças cardiovasculares. In: _. Medicina interna básica. Rio de Janeiro: Guanabara Koogan, 1998. p.52-54.

3 BECK, J.D. et al. Periodontal disease and cardiovascular disease. J. Periodontol., Chicago, v.67, n.10, p.1123-1137, 1996. Supplement.

4 FONG, I.W. Emerging relations between infectious and coronary artery disease and atherosclerosis. Can. Med. Assoc. J., Ottawa, v.163, n.1, p.49-53, 2000. Supplement.

5 HUJOEL, P.P. et al. Periodontal disease and coronary heart disease risk. JAMA: The Journal of the American Medical Association, Chicago, v.284, n.11, p.1406-1410, 2000.

61999 International Workshop for a classification of periodontal diseases and conditions. Ann. Periodontol., Chicago, v.4, n.1, p.7-38, 1999.

7 MACKENZIE, R.S.; MILLARD, H.D. Interrelated effects of diabetes, arteriosclerosis and calculus on alveolar bone loss. J. Am. Dent. Assoc., Chicago, v.66, p.191-199, 1963.

8 MATTILA, K.J. et al. Association between dental health and acute myocardial infarction. Br. Med. J., London, v.298, n.6676, p.779782, 1989.

9 MATTILA, K.J. Dental infections as a risk factor for acute myocardial infarction. Eur.
Heart J., London, v.14, p.51-53, 1993. Supplement K.

10 DE STEFANO, F. et al. Dental disease and risk of coronary heart and mortality. Br. Med. J., London, v.306, n.3, p.688-691, 1993.

11 JOSHIPURA, K.J. et al. Poor oral health and coronary heart disease. J. Dent. Res., Alexandria, v.75, n.9, p.1631-1636, 1996.

12 PAUNIO, K. et al. Missing teeth and ischaemic heart disease in men aged 45-64 years. Eur. Heart J., London, v.14, p.54-56, 1993. Supplement.

13 HUJOEL, P.P. et al. Examining the link between coronary heart disease and the elimination of chronic dental infections. J. Am. Dent. Assoc., Chicago, v.132, n.7, p.883-889, 2001.

14 BRODALA, N. Porphyromonas gingivalis bacteremia induces systemic inflammation and atherosclerosis in pigs. J. Periodontol., Chicago, v.73, n.8, p.969-970, 2002.

$15 \mathrm{CHIU}$, B. et al. Multiple infections in carotid atherosclerotic plaques: Part 2. Am. Heart J., St.Louis, v.138. n.5, p.S534-S536, 1999.

16 HARASZTHY, V.I. et al. Identification of periodontal pathogens in atheromatous plaques. J. Peridontol., Chicago, v.71, n.10, p.15541560, 2000.

17 HERZBERG, M.C.; MEYER, M.W. Effects of oral flora on platelets: possible consequences in cardiovascular disease. J. Periodontol., Chicago, v.67, n.10, p.1138-1142,1996. Supplement. 
$18 \mathrm{WU}$, T. et al. Examination of the relation between periodontal health status and cardiovascular risk factors: serum total and highdensity lipoprotein cholesterol, C-reactive protein, and plasma fibrinogen. Am. J. Epidemiol., Cary, v.151, n.3, p.273-282, 2000. 19 LOOS, B.G. et al. Elevation of systemic markers related to cardiovascular diseases in the peripheral blood of periodontitis patients. J. Periodontol., Chicago, v.71, n.10, p.15281534, 2000.
20 McCARTHY, M.F. Interleukin-6 as a central mediator of cardiovascular risk associated whit chronic inflammation, smoking, diabetes, and visceral obesity: down-regulation with essential fatty acids, ethanol and pentoxifylline. Med. Hypotheses, Edinburgh, v.52, n.5, p.465477, 1999.

21 KWEIDER, M. Dental disease, fibrinogen and white cell count, links with myocardial infarction? Scott. Med. J., Edinburgh, v.38, n.3, p.73-74, 1993. 